\title{
The evaporation loss from water reservoirs of Uzbekistan
}

\author{
Furkat Gapparov, Sobir Kodirov ${ }^{*}$ and Safar Mansurov \\ Tashkent institute of Irrigation and Agricultural Mechanization Engineers, hydrology department, \\ 100000, Tashkent, Uzbekistan
}

\begin{abstract}
The article deals with the results of the calculation of annual evaporation losses from the open water surfaces of reservoirs of Uzbekistan. For the estimations, we used the formula of the dependence of the temperature of open water surfaces of the reservoirs with the air temperature and average depth of them, and the tendency of air temperature change over time. The relationship between the wind speed above reservoirs and the weather station was defined.
\end{abstract}

\section{Introduction}

Only with applying irrigated agriculture method in the Republic of Uzbekistan, it is possible get high yields of agricultural crops, so the country's water resources should be used efficiently, economically. This requires accurate metering and control of water use.

Changes in the streamflow of water in rivers due to global climate change, being as a main source of irrigation, creates more issues in redistribution of water resources in the region. To eliminate the negative consequences of the non-compliance of the flow fluctuation schedule with the schedule for changing agricultural water needs, irrigational reservoirs were built, in which water accumulates when there is an excess streamflow, it is spent on increasing irrigation demands.

The schedule of filling and drawdown of the reservoir is based on the water balance equation of the reservoir. One of the expenditure components of the water balance of the reservoir is evaporation from its surface.

In general, evaporation rate is controlled by the availability of energy at the evaporation surface, and the ease with which water vapor can diffuse into the atmosphere. A different complex physical process are responsible for the diffusion, but the physics of water vapor loss from open water surfaces and from the soil and crops is essentially identical [1].

In the article we dealt and proposed the dependence between open water surface temperatures of the reservoir with the air temperature, wind direction, its changes, and average annual air temperature and water depth of the reservoir. The dependences between the wind speed on the reservoir and the weather station are obtained. The results of the calculation of annual evaporation from irrigation reservoirs of Uzbekistan are given.

\footnotetext{
*Corresponding author: smqodirov@mail.ru
} 
Significant liquid water losses from reservoirs reduce their reliability as irrigation sources. Dependability of constructions is a characteristic of preserving them in time and within the settled limits of the values of all parameters characterizing the ability to perform the required functions in the specified modes, conditions of use and maintenance.

Small reservoirs have to provide water supply to irrigated areas within the necessary volumes and regimes for agricultural crops.

Evaporation losses are one of the loss components of the water balance of the reservoir, which is completely irrecoverable.

Currently, for practical assessment of evaporation from water bodies namely water reservoirs, various methods have been proposed: water balance equations, heat balance methods and empirical formulas [2].

The best way to immediate assessment of the integral value of evaporation from a reservoir (without the applying of averaging the fields of certain elements of heat or moisture exchange) is the method of calculating evaporation from the water balance equation. Losses for evaporation from the reservoirs of Uzbekistan are significant both due to climatic conditions and for other reasons, including the shallow conditions of them.

\section{Materials and methods}

In this article method of Hydrometeorological research processing of the data which were obtained by using of mathematical statistics and comparison of the calculated data with the results of field data was applied.

The estimation by the proposed method can be performed by determining the predicted evaporation from open water surface of the reservoir. In this case, the average annual data on air temperature, absolute humidity and wind speed, if there is lack of information that can be used to calculate their predicted values.

It is possible determine the actual value of evaporation for the past month or year. In this case, the calculation uses data from measurements of air temperature, its absolute humidity and wind speed with the help of thermometers, psychrometers and anemometers.

For overall 55 reservoirs of Uzbekistan we carried out evaporation calculations of determining of the total volume of losses from reservoirs. Based on observations of humidity, wind speed and other climatic characteristics for the last 10 years at meteorological stations and lake meteorological stations estimations were made [3] with taking into account the volumes of reservoirs, the surface areas and average depth. For some reservoirs in the foothill areas, the formula of the SHI (State Hydrological Institute, Russia) was applied. [4].

When calculating evaporation from open water surface of reservoirs according to the SHI formula or similar formulas, it is necessary to know the temperature of the surface area of reservoir and the wind speed. In the absence of observations for the water temperature on existing or projected reservoirs, it is recommended to take into account the temperature of the water reservoir analogue.

Hydrological yearbooks contain data of the temperature of the surface area only for a few reservoirs of Uzbekistan. It is often hardly possible to find an analogue reservoir.

A first-order correlation equation [4] of the following form was compiled:

$$
\frac{t_{\text {air }}}{-t_{\text {air }}}=A+B \frac{t_{\text {air }}}{\bar{t}_{\text {air }}}+C \frac{\left(t_{\text {air }}\right)_{n+1}-\left(t_{\text {air }}\right)_{n-1}}{\bar{t}_{\text {air }}}
$$

Where ( $\mathrm{t}$ air) $\mathrm{n}+1$ and ( $\mathrm{t}$ air) $\mathrm{n}-1$ are average air temperatures for the following and preceding calculated months. The last addend is necessary to take into account the fact that when the air temperature rises, the water heats up more slowly due to the large heat 
capacity of the water, and as the air temperature decreases, the water cools down more slowly.

Parameters of A, B and C were determined by applying least squares method from observations of the surface water layer in the reservoirs of the Republic of Uzbekistan and air temperature according to the observations of the meteorological stations closest to the reservoirs.

To determine the surface temperature of water reservoirs, we derived a statistical dependence between water surface temperature and air temperature observations, which are systematically conducted at meteorological stations [5].

According to abovementioned relationship the formula is as follows:

$$
t_{\text {wat }}=0,78 t_{\text {air }}+0,17 \bar{t}_{\text {air }}-0,19 \frac{\bar{h}}{h_{n r l}}\left[\left(t_{\text {air }}\right)_{n+1}-\left(t_{\text {air }}\right)_{n-1}\right]
$$

Where:

$$
\begin{gathered}
T_{\text {water }} \text { and } t_{\text {air }} \\
- \\
t_{\text {air }}
\end{gathered}
$$

$\left(t_{\text {air }}\right)_{n+1}$ and (

$\left.t_{\text {air }}\right)_{n-1}$

$$
\begin{gathered}
\bar{h} \\
h_{n r l}
\end{gathered}
$$

- the average temperature of water and air;

- average annual air temperature.

- assessed average air temperature for the following month and previous month.

- monthly average water reservoir depth

- average water reservoir depth at normal retaining level

At current reservoir in determining the evaporation from water surface of the reservoir in the absence of observations for the wind speed, we used the long-term observations of the wind speed one of the nearest meteorological stations to our object.

According to the research it was identified that to pick up a appropriate weather station where observations were made for at least 20 years, it is necessary to establish the presence of a correlation relationship between the wind speeds at this weather station and the reservoir by conducting synchronous, short-term (preferably within a year) observations on them.

To check the tight connection of the correlation relationship, we used recommendations of Brooks et.al. [7].

\begin{tabular}{|c|c|c|c|c|c|c|c|c|c|}
\hline \multicolumn{3}{|c|}{$\begin{array}{l}\text { Number of sim. } \\
\text { observations, } \mathrm{n}\end{array}$} & 10 & 12 & 14 & 16 & 18 & 20 & 25 \\
\hline \multicolumn{3}{|c|}{ Correlation coef., $K$} & 0,632 & 0,576 & 0,532 & 0,497 & 0,468 & 0,444 & 0,396 \\
\hline 30 & 35 & 40 & 45 & 50 & 60 & 70 & 80 & 90 & 100 \\
\hline 0,361 & 0,334 & 0,312 & 0,294 & 0,279 & 0,254 & 0,235 & 0,220 & 0,207 & 0,197 \\
\hline
\end{tabular}

The value of the calculated correlation coefficient depending on the number of pairs of observations of wind speed is compared with the tabular one (Table 1). The table shows the values of $\mathrm{K}$ for a significance level of $5 \%$.

Table 1.

If the value of the calculated coefficient turns out to be equal to or greater than the table value, then the correlation relationship should be considered proven and the observations of 
the wind speed at the meteorological station can be used to determine the wind speed at the reservoir.

The relationship between the wind speed on the reservoir and the weather station is given by the equation:

$$
V_{w b}=\frac{\sum_{i=1}^{n} y}{n}+\frac{\sum_{i=1}^{n} x y-\frac{\sum_{i=1}^{n} x \sum_{i=1}^{n} y}{n}}{\sum_{i=1}^{n} x^{2}-\frac{\left(\sum_{i=1}^{n} x\right)^{2}}{n}}\left(\bar{V}_{w M}-\frac{\sum_{i=1}^{n} x}{n}\right),
$$

Where $\mathrm{V}_{W B}$ and $\mathrm{V}_{W M}$ - are average monthly or decade long-term wind speed observations at the reservoir and meteorological station (for the number of observations at the meteorological station);

$$
x, \bar{x}=\frac{\sum_{i=1}^{n} x}{n}-\text { wind speed and average wind speed at a meteorological station over the }
$$
period of simultaneous observations at the reservoir;

$y, \bar{y}=\frac{\sum_{i=1}^{n} y}{n}$ - wind speed and average speed on the reservoir over the period of simultaneous observations;

$n$ - The number of simultaneous wind speed observations.

Annual water losses through evaporation are determined at the condition of initial designed of schedule for each reservoir filling and drawdown processes.

Depending on the average depth of the reservoir annual evaporation losses in percentage of the total volume are graphically shown in Fig. 1.

\section{Results}

For the Syrdarya and Amudarya River basins the smoothing curves determined by the least squares method separately for the reservoirs as follows: 


$$
\frac{\Delta W}{W} 100 \%=50,171 h^{-0.9199} \text { and } \frac{\Delta W}{W} 100 \%=62.951 h^{-0.9146}
$$

Where:

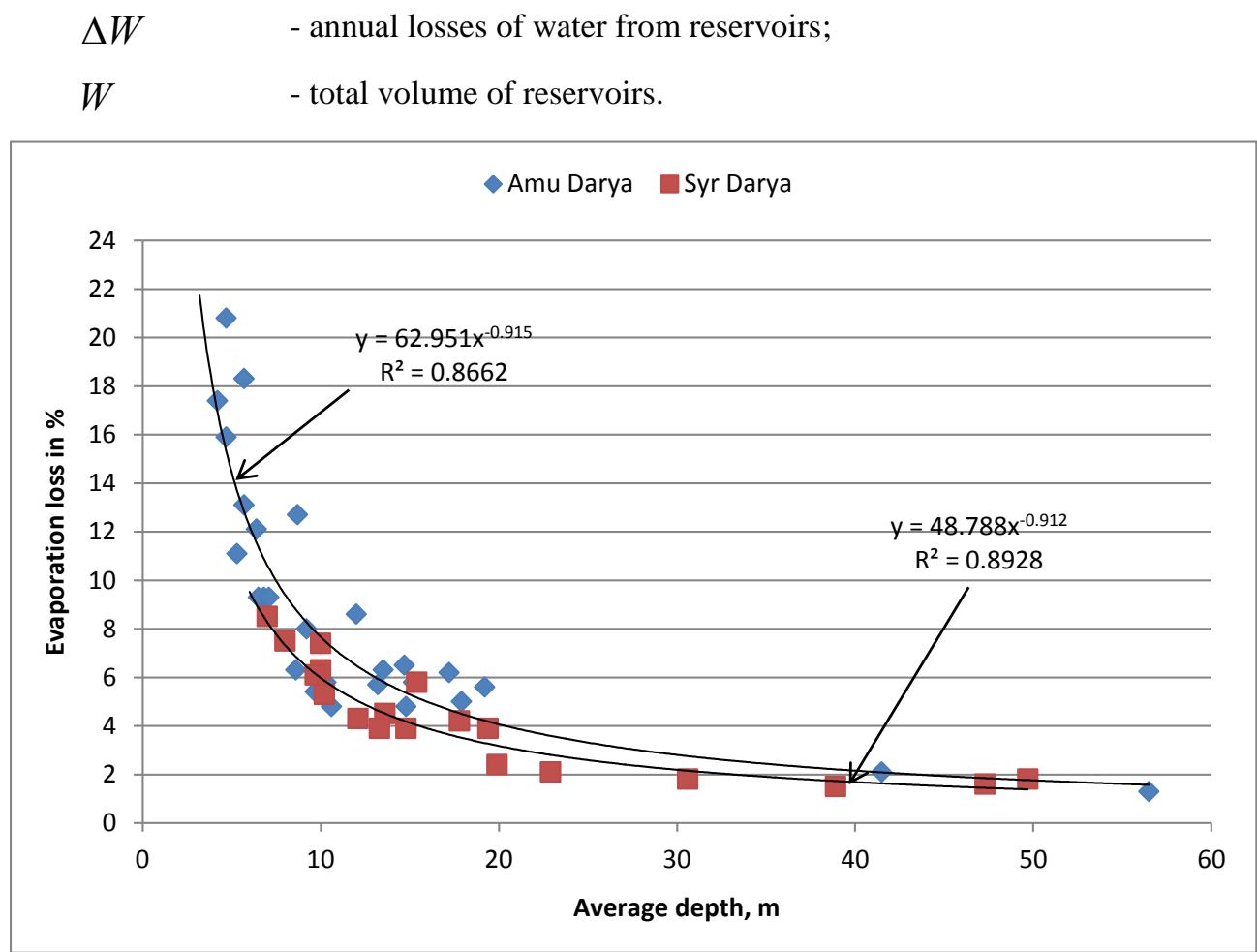

Fig.1. The dependence between evaporation and average depth of reservoirs.

As it was expected, the relative losses through evaporation decrease rapidly with increasing of the depth.

When an average depth is more than $16 \mathrm{~m}$, evaporation losses are less than $5 \%$ of the reservoir total volume. At a considerable depth, its changes have little influence on the amount of evaporation.

The sum losses from the reservoirs of the Syr Darya River basin with a total volume of about 5 billion $\mathrm{m} 3$ constitute $2.1 \%$ of their volume. A relatively small amount of losses is associated with the presence of such deep reservoirs as Andijan, Akhangaran, Charvak, Karkidon, Zaamin.

\section{Conclusions}

Fig.1. depicts clear dependence between average depth and evaporation loss. With decreasing depth evaporation loss is significantly increasing. Which can be explained under the condition of shallow water reservoirs and low relative humidity contributes more losses of liquid water from reservoirs.

The overall losses from the reservoirs of the Amudarya River basin with a total volume of 14 billion $\mathrm{m}^{3}$ make up $8.4 \%$ of their volume. Large evaporation losses are can be explained not only by the climatic conditions in which the reservoirs are located there, but also by the presence of such reservoirs as the South Surkhan, Aktepe, Chimkurgan, 
Shorkul, Tudakul and Tyuyamuyun, that except for the latter have an average depth of $9 \mathrm{~m}$ and less.

Obtained results significantly simplifies the informations of complex situations about water losses through evaporation that is used by the reservoir operations services and helps to estimate the amount of water losses for evaporation from reservoirs of the Republic of Uzbekistan, as well as to develop measures for their reduction.

\section{References}

1. Maidment David R. editor in chief. "Handbook of hydrology”. Chapter 4, (1993)

2. "Reliability of technologies". Basic concepts. Terms and Definitions. GOST 27.00289.- Moscow.

3. "Instructions for estimations of evaporation from the water surface". - Leningrad. House of Hydrometeorological Editions,.- 84 pp., (1969)

4. Gorelkin, N.E., Nikitin, A.M., "Evaporation from the water bodies of Central Asia”. Works of CARRIHM. -.- Annual ed. 102.-8-24 pp., (1985)

5. Gapparov F.A., "Determination of water temperature in the calculation of evaporation from reservoirs". Issues of hydrotechnical constructions in mountaineons conditions. Reports of young scientists and specialists.-Kobuleti,. - 34 pp., (1989)

6. Mitropolky A.K., “The techniques of statistical calculations”. - Moscow. - 480 pp., (1961)

7. Brooks K., Carousers N., “Application of statistical methods in meteorology”. Leningrad: House of Hydrometeorological Editions,. - 416 pp., (1963) 